\title{
Hard Work in Soft Regulation: A Discussion of the Social Mechanisms in OHS Management Standards and Possible Dilemmas in the Regulation of Psychosocial Work Environment
}

\section{Pernille Hohnen'}

Associate Professor, Department of Culture and Global Studies, Aalborg, Denmark

\section{Peter Hasle}

Professor with Specific Responsibilities, Center for Industrial Production, København SV, København, Denmark

\section{Anne Helbo Jespersen}

Industrial PhD student, Bureau Veritas Denmark and Aalborg and Center for Industrial Production, København SV, København, Denmark

\section{Christian Uhrenholdt Madsen}

MSc Scientific Assistant, Center for Industrial Production, København SV, København, Denmark

\begin{abstract}
Certified occupational health and safety (OHS) management systems have become a global instrument in regulation of the work environment. However, their actual impact on $\mathrm{OHS}$ - in particular on softer psychosocial issues in the work environment - has been questioned. The most important standard of OHS management is OHSAS I800 I, which has recently been supplemented with a British publically available guideline (PAS 1010) focusing specifically on psychosocial risk management. On the basis of the international literature on management standards, the present paper analyses OHSAS 18001 and PAS 1010 in order to understand the mechanism by which they work. The paper takes a social constructionist approach conceptualizing standards and their expected mechanisms as socially constructed-based on a particular kind of knowledge and logic - although they are presented as objective. Such a constructionist approach also emphasizes how standards transform specific work environment problems into generic procedures that can be audited. In the case of OHS standards, both the work environment in general and the psychosocial risks in particular are transformed into simple monocausal auditable relations whereby the complexity of psychosocial work environment issues seems to disappear. The new PAS 1010 guideline, which is particularly focusing on regulation of the psychosocial work environment, only partly succeeds in solving these shortcomings of OHSAS 18001.
\end{abstract}

\section{KEY WORDS}

Standards / Regulation / Psychosocial working environment / Document analysis

\footnotetext{
${ }^{1}$ Hohnen@cgs.aau.dk
} 


\section{Introduction}

"Standards quite often fall into the category of 'boring things' that fail to elicit much attention and scrutiny. Although standards are often formally (or legally) negotiated outcomes, they also have a way of sinking below the level of social visibility, eventually becoming part of the taken-for-granted technical and moral infrastructure of modern life. Ironically however, it may be just this relative invisibility that gives standards their "inertia." (Timmermans \& Epstein, 2010: 71)

As Timmermans and Epstein indicate, standards have grown from a topic of interest mostly to engineers and technicians into getting an increasing impact on the organization of modern social life, including contemporary working life (Boiral, 2012; Brunsson $\&$ Jacobsson, 2012). Within the field of work environment, standards have moved from having limited influence as standards in adjoining fields, for example, ISO 9000 and ISO 14000 to being a principal form of regulation by applying occupational health and safety (OHS) management standards. The most widespread standard in the field of work environment is the OHSAS 18001, a semi-international standard for management of OHS originally developed by the British Standards Institute (BSI). OHSAS 18001 is supposed to manage all aspects of the work environment. However, recent studies have identified several shortcomings in the way standards manage psychosocial work environment problems (cf. Hohnen \& Hasle, 2011; Leka et al., 2011). Recently, a British public guidance (PAS 1010) has appeared as a supplement to OHSAS 18001 specifically addressing psychosocial work environment risks. In spite of the fact that PAS 1010 can be viewed as a significant contribution to the solution of the problems in OHSAS 18001, it also raises some dilemmas that seem related to the ways standards work.

Sociological researchers suggest that prevailing research tends to conceptualize standards as either totalizing narratives dehumanizing social life or weak and insignificant forms of regulation (Lampland \& Star, 2009; Timmermans \& Epstein, 2012). Following this, Timmermans and Epstein (2012) recommend more empirical analyses in specific domains in order to shed light on the implications of standardization as a regulatory tool. This article is an attempt to carry out such an empirical analysis within the field of psychosocial work environment. We do this by identifying particular significant characteristics of standards from a social constructionist analytical perspective (Ahrne \& Brunsson, 2005; Berger \& Luckman, 1966; Brunsson \& Jacobsson, 2000; Brunsson et al., 2012; Giddens, 1990) Viewed from this perspective, the development of standards is not purely technological and using standards as a regulatory instrument involves more than just the (technical) specifications stipulated by the standard. For example, audits as a basic component in standards rely on a certain type of presumably objective calculation of risk. In order to carry out audits, therefore, a certain kind of knowledge base is created. Audits have therefore been viewed as constitutive of the work environment that they are supposed to monitor (Power, 1996, 1997, 2003). Standards can, as we shall see, be conceptualized as international, abstract expert systems usually developed by private organizations, functioning as voluntary rules of conduct as well as (political) instruments of control (Brunsson \& Jacobsson, 2000). Standards are also a specific form of governance and coordination related to an increasingly globalized market.

The structure of the paper is as follows. After a brief description of the methodology, we define international standards and outline the theoretical perspective of the 
paper. This is followed by an analysis of the social mechanisms in standards in a sociological regulatory perspective. After this, we turn to the empirical part that consists of an analysis of the prevailing international OHS standards: OHSAS 18001 and PAS 1010. The general aim is to depict possible dilemmas related to the application of international standards to the specific domain of psychosocial work environment regulation. We conclude by returning to a discussion of standards as a regulatory form and their limitations.

\section{Methodology}

The paper critically examines social processes and discursive logics involved in the regulation of OHS by international standards with a particular focus on the psychosocial work environment. The complex psychosocial work environment has proved particularly difficult to regulate by prevailing OHSAS standards because of their multicausal, subjectively experienced, and contextual nature that contrasts the monocausal and technical OHS issues, which the standards were originally aimed to address (Hohnen \& Hasle, 2011; Leka et al., 2011). In the paper, we analyze standards as written documents. The implication of this is that the analysis can only shed light on the type of knowledge and assumed logic that can be related to the standards and the construction of standards as text but not on how standards are implemented and work in practice. In the article, we apply the concept "social mechanism," which we define as "an inherent causal potential in a given social context, e.g. a causal potential that, integrated into a particular knowledge context, creates certain direct or indirect reactions or changes." This definition is inspired by an understanding of mechanisms described by Pawsons (2006), as "semi-regularities."

The first part of the analysis is a discussion of mainly theoretical organizational studies on standards as a type of regulation. Here, we analyze sociological/anthropological studies that focus on regulation in a broad sense, including types of knowledge, types of logic, and reasoning as well as the overall process of creating standards (Brunsson \& Jacobsson, 2000; Hohnen \& Hasle, 2011; Jacobsson, 2000; Power, 1996, 1997; Timmermans \& Epstein, 2012), and we enhance some of the mechanisms of standards that have been pointed out in the literature.

The second part of the paper is an analysis of the concrete documents related to OHSAS 18001 and PAS 1010 in order to dig out the possible social mechanisms of standards. OHSAS 18001 is strategically chosen because it claims to deal with psychosocial work environment and at the same time reflects intrinsic mechanisms of a range of international standards such as ISO 9000 and ISO 14001 (Jacobsson, 2000). Furusten (2000) suggests furthermore that standards can be divided into two categories: "partial standards," that are essentially recommendations, and "mandatory standards," that organizations need to follow in order to be certified according to the standard. OHSAS 18001 can be categorized as a mandatory standard, while PAS 1010 as a guideline can be classified as a partial standard.

PAS 1010 not only aims to create guidelines, which are compatible with the OSH (occupational safety and health) standards on the one hand, but also aims to address deficiencies (identified in earlier studies as particularly apparent when attempting to regulate psychosocial work environment issues) on the other hand. Where OSH standards work 
with "abstract" and decontextualized knowledge and perceive OSH risks as monocausal, "technical," and "measurable," PAS 1010 attempts to address psychosocial work environment risks as complex, contextualized, and subjectively experienced forms of knowledge (BSI 2011). In other words, an analysis of PAS 1010 is also an analysis of the potential of standards to reconcile two very different types of knowledge.

The analysis of the standards is inspired by discourse analysis and aims at understanding the structural as well as cultural conditions that standards epitomize (see, e.g., Power, 1996, 1997). The analysis focuses on the concepts and types of logic that standards entail, how work environment is addressed and monitored, that is, what areas of work environment are considered relevant within the management system, and what types of monitoring are considered reliable. In accordance with the overall social constructionist framework of the paper, we supplement the analysis of the documents themselves with a brief analysis of their creation, including information about the main stakeholders as well accounts of problems or conflicts that characterizes the process of creation. For these accounts, we rely on several sources (Ahrne et al., 2000; Frick \& Kempa, 2011; Leka et al., 2010).

\section{Defining standards as a form of regulation}

Brunsson and Jacobsson (2000) discuss standards from a sociological perspective where they conceptualize regulation as "rule-making in a broad sense" as well as a form of "organized governance" (ibid. 12). On the basis of the notion of rule-making, Brunsson and Jacobsson distinguish between three fundamental types of regulation: directives, norms, and standards. Norms are internalized rules that are implicit (one does not have to reflect upon them), whereas directives are explicit, mandatory rules often combined with sanctions in case rules are not followed. Standards are presented as a combination of the two. Standards differ from directives because they are (or are claimed to be) voluntary, and they differ from norms because they are explicit and because they have an evident source. The degree in which a standard is adhered to does not depend on any hierarchical authority, but on whether the standard is regarded as relevant and appeals to the users or adopters of the standard (ibid. 13). It should be noted though that the standards become a directive for the employees in the organization where it has been adapted. So, standards provide explicit rules that are voluntary, and they do not have power to enforce, rather they must convince potential users of the usefulness. Standards can hence be described as non-hierarchical, voluntary, and usually global pieces of advice. Following Brunsson and Jacobsson (2000), we use the following definition:

"Standards are rules that are claimed to be voluntary, have a source and are explicit." (ibid. 13)

However, although standards may be conceptualized as a certain type of regulation, they are often used in combination with both directives and norms. In nearly all countries, a certified OHS management system requires compliance with national OHS regulation (Frick \& Kempa, 2011), and in some cases, national authorities may decide to include the standard in its legislation such as in Denmark, where organizations with a certified OHS management system are exempted from regular labor inspection. The content of 
the standard may over time develop into social norms about how the work environment is handled. Viewed from a social constructionist perspective therefore, standards must be looked at as entities that may operate in a range of ways, for example, as instruments of control, as global coordinators, and as having a normalizing and often homogenizing power. They must therefore be studied within the external as well as internal sociopolitical context in which they are produced and operate.

\section{Conceptualizing generic socially constructed mechanisms in standards}

Standards as a form of social regulation include a concern with the social processes involved in the creation of standards as well as a focus on the type of actors, knowledge, norms, and authority that standards promote (Boiral, 2010; Brunnsson \& Jacobsson, 2000; Brunsson et al., 2010; Star \& Lampland, 2009; Timmermans \& Epstein, 2010) as well as an analysis of audits (Power, 1996, 1997, 2003). The conceptualization of standards as a means of regulation in this perspective goes beyond the analysis of the particular standards and their implementation by aiming to understand the kind of transformations of responsibility, knowledge, and authority that standards epitomize. In the following, we take a closer look at what we consider to be the significant characteristics of standards in terms of how they implicitly as well as explicitly influence the regulation of OHS.

\section{Production and reproduction of standards}

In terms of understanding the specific mechanisms inherent in the production of standards, we need to look at the production process. Most standardizing companies are non-governmental organizations such as ISO (International Organization for Standardization) and BSI (the British Standards Organization). In addition, governments may also issue standards and international governmental institutions are quite active standardizers. In particular, EU is an active standardizer by issuing a large number of white books (soft law) or by delegating to standardizing organizations instead of issuing directives (Brunsson \& Jacobsson, 2000: 2-4). Often groups of professionals come together as authorized experts in the construction of a standard. Haas (1990: 41) terms such communities "epistemic" referring to groups who "share a common commitment to a causal model as well as a common set of political values." Following Haas, they are also united by a belief that their particular model will promote human welfare and therefore should be translated into policies (Haas quoted in Jacobsson, 2000: 48). It is important to emphasize, however, that composition of such groups is accidental and often dominated by private firms that can afford the resources to participate in the development of standards.

\section{Content and operation of standards}

Standards as a form of regulation have specific characteristics related to agency, authority, and knowledge. Jacobsson (2000: 41) and Power (1996, 1997) note as a significant feature of standards that they are based on so-called "expert systems" 
and "expert knowledge." Expert knowledge refers to the fact that knowledge in standards can be characterized as technical and rational and usually derives from general ideals rather than actual practice (Jacobsson, 2000). Standards are therefore said to transform knowledge into rules that are abstract, general, and recorded in writing. When this kind of knowledge becomes embedded in rules set by the standard, it tends to appear self-justifiable (ibid.). In addition, standards are usually built on rules about monocausal technical solutions also when addressing issues that involve more complex non-technical and/or political issues. Standards have a high level of abstraction, and Jacobsson paraphrasing Giddens (1990) points out that standards and the knowledge that is generated by standards is de-contextualized in space and time (Jacobsson, 2000). The problem is that not all kinds of knowledge are easily stored in this way and consequently that practice-near and tacit knowledge is not included in the standards.

The transformation of knowledge into technical rules also tends to promote depolitization of standardization:

"Some kind of rules that were previously considered politically important are now set by the European standardizing organisations, and thus by experts who might be representatives of companies, interest groups, or public agencies." (Jacobsson, 2000: 45-46)

The consequence is that standardization creates order without (political) responsibility. The tendency for political issues to migrate to the technical sphere is both promoted by the production process of standards and by the fact that standards regulate former political decisions:

"In Sweden, to take one example, the determination of what occupational health and safety actually meant was precisely delegated to employer associations and trade unions, although in principle politicians could always intervene. Now decisions in this area have largely been turned over to transnational groups of experts; it is difficult to ascertain who belongs to these groups and how they function. The politicians remain responsible, but the scope of their influence has been reduced.” (Jacobsson, 2000: 48)

On top of this, it is difficult to alter standards, because there is no formal channel of influence and standards do not answer to anyone. Responsibility (including political responsibility) is therefore transferred to individual actors such as organizations and their managers and employees. In this way, standardization promotes depolitization. Another consequence of that regulation is individualized making it difficult to oppose or complain about standards.

"Markets and standardization generate fewer complaints than organizations. In organizations most people can blame someone else, whereas market actors or those who follow standards have themselves to blame.” (Brunsson \& Jacobsson, 2000: 25)

The consequence is that standards do not offer clear channels of voice for users, and the responsibility for the impact of a particular standard as well as the relevance of procedures or policies rests entirely with the users of the standard. 


\section{Procedures and audits as key elements}

"Many standards are primarily concerned with procedures and presentations rather than with production, products or the effects of these. A number of standards concerning the work environment refer not to the work environment itself but to the plans and procedures organizations should develop for dealing with related issues." (Jacobson, 1993, quoted in Brunsson \& Jacobsson, 2000)

Following Brunsson and Jacobsson (2000), the rules in standards are mostly concerned with plans and procedures for regulating and documenting the subject matter, for example, work environment rather than being concerned with the extent to which the particular organization secures a safe and sound work environment. This has implications on several levels. First, they tend to resemble what Douglas (1992) has termed "rituals of verification" rather than actual verification because the focus is on verifying the establishment of procedures rather than on the compliance with the requirements that these procedures are expected to ensure, for example, a protection against psychosocial risks at work. Second, and in continuation of this, it can be argued that audit regimes indirectly create what Hertfeld (1992, quoted in Strathern, 2000) has called bureaucratic "indifference" by legitimizing audit systems as a way of securing a certain quality of the work environment, which in turn makes it difficult to criticize the systems or sustain the idea that alternative assessments may exist. Finally, Power (1997) suggests that "good performance" is conflated with "the visibility of good performance" due to the significance of external auditing where the ability to demonstrate solutions shape internal policies and initiatives (see also Hohnen \& Hasle, 2011).

From a social constructionist perspective, it is possible to identify some interesting internal mechanisms of the audit-based systems developed in international standards. Power $(1996,1997,2003)$ suggests that such auditable systems are not merely there but are constructed as a part of the implementation of the certified management system. He points to two interrelated processes. First, audits require a certain kind of expert knowledge that is considered legitimate knowledge by the system, for example, reporting near misses or measuring psychosocial work environment by yearly questionnaires. Second, an auditable work environment, based on the kind of (technical) knowledge necessary in the auditing process, is actively created. The constructionist approach of Power thereby entails the idea that auditing is a process that actively creates the work environment that it supposedly monitored. In other words, audit systems transform the subject matter of the management systems that it monitors into a distinctive type of procedures and technologies that are recognizable and auditable. There are several implications of this. First, audits are generally more focused on the presentation and procedures documenting work environment policies rather than with the compliance with such prevailing forms (Power, 1996). Second, and in continuation of this, a certain set of problems, corresponding to the available set of procedures as well as available solutions, are constructed as the most significant issues, while alternate issues remain unidentified (Hohnen \& Hasle, 2011).

\section{The relationship between abstract rules and local practice}

Standards are rules storing abstract, expert knowledge; hence, standards are based on ideal general de-contextualized cases; they are voluntary and standardizers have no 
authority in terms of enforcing compliance with standards. Therefore it is far from clear why people should follow standards, and if they do, how these generalized forms of knowledge stored in procedures are translated into practice. The challenge of making standards appeal to a differentiated world of customers seems to result in standards being general and abstract rather than specific and contextualized:

"Standards are by definition 'rules for the many.' As such they are necessarily abstract to some degree and general in scope, and cannot cater for the idiosyncrasies of the organizations to which they apply." (Brunsson et al., 2012: 621)

It follows therefore that there is a necessary process of adoption involved where general rules are transformed into localized rules. Such a process of adaption may not only require changes in the local context, but may also result in a transformation of the standard itself. In its essence, this is a two-way translation process involving both the translation of general rules into concrete practices and a translation back to the more general requirements in the standards in order to demonstrate that the standard is being followed (Brunsson et al., 2012: 621-622). It should be noted, however, that we do not regard this process as a closed process in quite the same way as Brunsson et al. did (2012). Although the preference for abstract rules and the above-mentioned logic of an almost self-fulfilling prophecy of local practice compliance with the abstract standard, we suggest that this rather functionalist vision may be challenged in practice. Abstract expert systems may also create a real space for developing local practices that may address local work environment issues and create new solutions. The interaction between standards as rules and local practices does not take place in a closed social system.

The adaption of standards therefore tends to be based on local organizational interests, for example, actors may acquire influence and/or give their own strategies additional authority by adapting standards. The fact that standards are necessarily abstract and general in order to appeal to many different users therefore leads to great variation in implementation. On one hand, the demand for local adaption gives the actors a scope to form the concrete use of the standard into local needs, but on the other hand, this adaption will be influenced by the logics of the standard, for instance, by the need to make the work environment auditable. In addition, the more abstract the standard is that may imply wider application, the more difficult it becomes to specify compliance. Thus, abstraction appeals to users, but makes it more difficult to estimate when the requirements of the standard is met, and as adaption of documentation (language) is easier than adaption of practice, hence "what actors say is more influenced by standards than what they do" (Brunsson, 2000: 145).

\section{Summary: social implications of governing by standards}

Understanding standards from a sociological and organizational perspective reveals a number of generic mechanisms that have implications for the subject matter being regulated. First, standards are based on rules that have a source and that are explicit. The fact that standards are rule-based has consequences for the kind of knowledge base of standards, because not all knowledge is easily stored in rules. Technical knowledge and technical solutions are more compatible with standards, whereas more tacit and practical 
knowledge cannot be transferred into abstract rules. Standards therefore tend to focus on technical monocausal knowledge. An important consequence is a presentation of knowledge as objective and consensus oriented, making topics with conflicting interests and/or knowledge that are related to influence, position, and interests unnoticed. Second, standards focus on management systems that can be audited both internally and by external parties. In doing so, standards can be viewed as an example of what Giddens (1990: 79) terms "abstract expert systems" characterized by "disembedding" in the sense that social relations are no longer related to specific local contexts or communities, but are lifted out and based on more invisible systems of knowledge and social networks (1990: 21). A large part of social activities rely on systems (e.g., the internet; bank transfers; tax paying), which are invisible (and unknown) to the actors performing them. The knowledge base of such systems is abstract, decontextualized, and depersonalized. As a result, standards tend to be preoccupied with procedures, processes, and presentation rather than with subjects or products. Furthermore, controlling systems by audits seems to enhance such a focus on procedures by transforming other knowledge areas (about products or subjects) into a type of procedural/technical knowledge that can be audited. Third, abstract and decontextualized systems may be necessary in order to secure the general application, but it also makes a room for great variety. Abstract knowledge needs to be localized and translated into practice as well as translated back into general procedures/processes that are recognized in the standard and in auditing the system. Therefore, in spite of the initial intention, variety in the form of local and national differences may be an unintended consequence of global standardization. A fourth aspect of international standards, which concerns us here, is the fact that they have been developed in a negotiation between influential stakeholders. To some extent, this may ensure widespread compliance; however, neither the recruitment of stakeholders nor the outcome of negotiations ensure, for example, that major findings of scholarly research form the basis knowledge of a standard.

\section{Empirical analysis of OHSAS I800I and PAS I0I0 as standards}

In the following section, we analyze how such social mechanisms are played out in the concrete example of OHSAS 18001 and the recent British Public guidance PAS 1010. In the analysis of OHSAS 18001, we focus on the standard itself but in addition to this also draw on prevailing literature. The analysis of PAS 1010 is based solely on the text, as no empirical research has yet been carried out.

\section{OHSAS I800I}

Occupational health and safety management started as part of the pre-World War II "safety movement" wherein predominantly large firms started to systematically attempt to reduce accidents (Heinrich, 1959). These systems were later developed into extensive management systems such as Du Pont safety management systems (Frick \& Wren, 2000; Hasle, 2010). In recent decades, these systems have developed into certified management systems and OHSAS 18001 is a response to an increasing global market demand for external accountability together with ISO 9000 and ISO 14000 (Jacobsson, 2000; Power, 
2008). In accordance with the principles of ISO 9000, OHSAS 18001 is characterized by the establishment of internal systems of management and control that are then audited and certified by external auditing agents. OHSAS 18001 is not an ISO standard (although this was attempted); instead, it became a British Institute Standard (BSI) in 1999 supported by 14 national standard issuing bodies (Frick \& Kempa, 2011). Since then, OHSAS 18001 has de facto performed as an international standard.

OHSAS 18001 addresses all occupational health and safety risks but does not explicitly mention the psychosocial work environment. Only once in the glossary do we find a reference to "mental conditions" when ill health is defined as "identifiable, adverse physical or mental condition arising from and/or made worse by a work activity and/ work related situation" (DS/OHSAS 18001, 2008: 3). It follows that the regulation of psychosocial work environment is assumed to be covered by the more general requirements in the standard for the creation, maintenance, and monitoring of an OHS management system within the individual organization. However, empirical studies have pointed out that the certified OHS management system does not necessarily secure a good psychosocial work environment in practice (Hohnen \& Granerud, 2010; Hohnen \& Hasle, 2011; Leka, 2011).

The OHSAS standard is based on a methodology known as plan-do-check-act (PDCA) (DS/OHSAS 18001, 2008: vi). To plan is "to establish the objectives and processes necessary to deliver results in accordance with the organizations" OHS policy. This among other things requires to "establish, implement and maintain a procedure(s) for the ongoing hazard identification, risk assessment, and determination of necessary controls" (DS/OHSAS 18001, 2008: 6). To do refers to the implementation of a range of processes that are meant to ensure performance (ibid. vi.). These processes include setting up a management system, for example, ensuring management commitment, procedures to make personnel aware of OHS risks, procedures for internal communication, procedures for workers participation in risk assessment, and ensure documentation of OHS policies as well and procedures to control such documents (ibid. 8-11). To check is "to monitor and measure processes against $\mathrm{OH} \& \mathrm{~S}$ policy objectives, legal and other requirements, and report the results" (ibid. 11). This requires the establishment of procedures to monitor and measure OHS performance on a regular basis, procedures to record, investigate and analyze incidents, procedures for dealing with nonconformities, and procedures defining requirements for actions in order to avoid recurrence (ibid. 12). Finally, to act means to take actions to continually improve OH\&S performance (ibid.). Management must review the OHS management system at planned intervals "assessing opportunities for improvement and the need for changes" (ibid. 14). The standard contains requirements (mainly focusing on the establishment and monitoring of the management system) that can be objectively audited, but it does not establish absolute requirements for OHS performance other than what is specified in the OHS policy of the particular company and/or in legal national requirements (DS/OHSAS 18001, 2008 vi). The standard explicitly states that it does not include specific OHS criteria or detailed specifications:

“This Occupational Health and Safety Assessment Series (OHSAS) Standard specifies requirements for an occupational health and safety $(\mathrm{OH} \& S)$ management system, to enable an organization to control its $\mathrm{OH} \& \mathrm{~S}$ risks and improve its $\mathrm{OH} \& \mathrm{~S}$ performance. It does not state specific $\mathrm{OH} \& \mathrm{~S}$ performance criteria, nor does it give detailed specifications for the design of a management system.” (DS/OHSAS 18001, 2008: 1) 
We suggest that part of the problems of OHSAS 18001 in addressing psychosocial work environment is directly related to some of the social mechanisms related in international standards. The lack of or specifications of factors influencing the psychosocial work environment and the PDCA methodology create a management system that focuses on abstract rules and procedures as well as the monitoring of such procedures by audits. In addition to this, there is an overall focus on the registration of "incidents of nonconformities" in both risk assessment and prevention and improvement. The OHS management system therefore can be categorized as an abstract expert system with a knowledge base focusing on monocausal technical incidents. The focus on the reporting and prevention of such incidents positions OHS risks as related to nonconformative behavior rather than more structural or more complex work and employment issues. The conclusion is that OHSAS 18001 builds on procedures that are abstract, and it is combined with a general notion of OHS risks as monocausal incidents or breaches of compliance with established technical procedures. The consequence is that more complex work environment issues are left out of sight. In order to be able to capture the more complex and softer issues of the psychosocial work environment, the individual organization needs to build on professional, contextual local knowledge that are not necessarily monitored as part of the system.

\section{PAS I0 I0: a solution to the regulation of psychosocial work environment by standards?}

As a supplement to OHSAS 18001, PAS (Publicly Available Specification) 1010 has been developed as a "Guidance on the management of psychosocial risks at the workplace" (BSI, 2010). The general background and motivation for the development of the guidance has been an acknowledgment of the changing nature of work accompanied by new and emerging types of risks to workers health and safety (Leka et al., 2011). Leka et al. (2011) state three observations concerning the prevailing regulation of psychosocial OHS risks by existing standards.

The first observation is that there is a lack of clarity and specificity of terminology suggesting a need for more precise concepts. In response to this, PAS 1010 focuses specifically on psychosocial risks, including work-related stress, psychosocial hazards, violence, harassment, and bullying as the main issues. Psychosocial risk is used as an umbrella concept covering other specific areas of psychosocial work environment. The specification of the issues includes the definition of work-related stress as caused by psychosocial hazards, violence, or harassment. Work-related stress may be caused by a single incident, for example, violence or the more complex psychosocial hazards that are defined as "interactions among job content, work organization and management, and other environmental and organizational conditions, and employees' competencies and needs" (ibid. 2.15).

The second observation is the fact that existing standards have trouble providing concrete guidance to organizations in the area of psychosocial risk management:

"Even though the OHSAS 18000 series and the ILO-OSH 2001 make specific reference to the psychosocial work environment, this reference is very brief and a preventive framework for action that organisations can adopt in practice is lacking, suggesting limited usability of these standards.” (Leka et al., 2011: 1054). 
Finally, a third observation concerns findings from several studies suggesting that European employers have found international standards less effective in the area of psychosocial work environment (ibid. 1054).

On the basis of these observations about current deficiencies, a group of organizations and researchers have developed PAS 1010. It is compatible with OHSAS 18001, ISO 9000, and ISO 14000, all of which are based on the PDCA approach. The creation of PAS 1010 took place as a negotiation among the different stakeholders, including the European Trade Union Confederation, the Engineering Employers' Federation, WHO, EU-OSHA, and British Standards Institution (BSI). It should be noted that in the process of creating PAS 1010, disagreement among these stakeholders developed regarding the possibility of creating a British Standard within the field of psychosocial work environment, and the end result has so far been the guidance and not a standard:

"However, some of the stakeholders involved in the Steering committee were not enthusiastic about this option and pointed out the limitations of an OHSAS type standard for psychosocial risk management. This reaction might have to do with the complex nature of psychosocial risks, the fact that they cannot be measured and managed in objective technical manner, and probably also the fact that ISO and OHSAS types of approaches are much better in managing operational problem solving than to address more structural issues such as work organization.” (Leka et al., 2011: 1054)

PAS 1010 offers guidance to and information about the management of psychosocial risks. It is based on principles (PDCA) similar to OHSAS 18001; however, it has a broader scope by also including work organization and management, which is not addressed by prevailing standards:

"The overall risk management process goes further and seeks to involve employees in the prevention of psychosocial risks and not by requiring them to simply change their perceptions and behavior." (BSI, 2011: 10)

Psychosocial risks are understood to have many causes and no quick fix solutions (BSI, 2010). In addition, the guidance includes a more participative approach than prevailing standards by emphasizing shared responsibility between employees and employers in assessing and reducing risks (Leka et al., 1055). The participative approach includes the recognition of employees as experts in their jobs:

"An effective model for psychosocial risk management places particular emphasis on the central status of the workers as 'experts' in relation to their own jobs.” (BSI, 2011: 9)

PAS 1010 can be viewed as an attempt to compensate for deficits in the prevailing OHS management standards by creating a supplement based on similar logics. PAS 1010 therefore offers a possibility for discussing the potential of using standards in an area in which the subject matter is multi-causal, complex, contextual, subjectively experienced, and to some degree political, and in this way, PAS 1010 deals with the regulation of topics that the sociological discussion of standards have pin pointed as being particularly difficult for international standards to address. 


\section{Discussion: does PAS 1010 create new standards?}

\section{The potential of PAS I0IO}

Both in the introduction to PAS 1010 and in the main body of the text the domain of psychosocial work environment and the management of psychosocial work risks are acknowledged to be of a qualitatively different nature than more traditional OHS issues. First, psychosocial work environment issues are complex. They often have several causes that may not be easily identified nor related to separate incidents, and they are interdependent in the way that problems of psychosocial nature often relate to and impact on other work environment areas. The result is (as stated in the text) there are no "quick fix" solutions to most psychosocial work environment issues. Second, psychosocial work environment issues relate to management and organization of work; hence, it touches on the managements' prerogative. In other words, the guidance does not confine psychosocial risks to individual workers' behavior or view such risks as being solvable alone by technical preventive tools. Third, a participative approach is advocated in order to identify and prevent psychosocial work environment risks for two reasons: the nature of psychosocial work environment problems are considered to be subjectively experienced as well as related to objective working conditions, and consequently workers are "experts" in their own psychosocial work environment. The participative approach rests on a qualitatively different notion of workers involvement compared with the traditional standards, and it specifies that workers' professional knowledge is the foundation of risk prevention within the management of psychosocial risks. The participative approach is also reflected in the guidance's acknowledgment of the role of social partners, the functioning of industrial relations as well as the condition that there is "the will of social partners to negotiate as equals" (BSI, 2011:3). Fourth, the guidelines rest upon the notion that a successful management of psychosocial risks must have a clear focus on the particular work context by drawing on prevailing scholarly knowledge of work domains influencing work-related stress and specifying key issues such as job content, workload, and influence/control (BSI, 2011:9). Finally and of importance to the specific monitoring and reviewing performance, the guidelines emphasize that both quantitative and qualitative information can be included in a systematic measurement of performance.

\section{The dilemmas in PAS I0I0}

Although PAS 1010 is not a British Standard, it is built on similar principles as OHSAS 18001, mainly the PDCA approach that implies relying on the development, monitoring, and reviewing of a range of procedures including internal as well as external audits. It follows that the generic social mechanisms inherent in international standards are also at work in PAS 1010, although it should be emphasized that no empirical studies of PAS 1010 have yet been published. However, by analyzing the text itself, it is possible to detect ambiguities related to the four generic social mechanisms in standards, which we discussed above: the technical knowledge base of standards, the focus on procedures and audits, the question of local contexts, and finally the creation of standards by stakeholder negotiations. 
Regarding the technical knowledge base, PAS 1010 is concerned with building a management system. Although this includes a concern with the psychosocial work environment as well as an expectation that the management system will (continuously) improve the psychosocial work environment, this focus has some implications that are related to the knowledge base of standards. PAS 1010 acknowledge that the psychosocial work environment is a product of interactions that cannot always be traced and are inseparable from subjective work experiences. It is also acknowledged that psychosocial risks are highly contextual and related to structural conditions, for example, work organization and employment conditions. However, the guidelines also specify that psychosocial risk management is systematic, evidence-informed as well as evidencedriven. We suggest that the term evidence-informed seems to indicate something different from the much stronger term evidence-based used in OHSAS 18001. However, it is not specified how this different terminology is to be understood and how it will create new ways of actually evaluating compliance and performance. The guidelines in other words attempt to combine the technical and decontextualized knowledge base with an inclusion of the local and complex social context. The ambiguity of these ways of conceptualizing knowledge is dealt with in different ways. For example, the most detailed and contextual information, for example, about what causes work-related stress is not in the text, but placed in an appendix. The fact that the actual text that outlines the requirements to performance is brief and lacks the contextualization that is described in the appendix, makes it easier to streamline risk assessment, and emphasizes the possibility of creating a clear knowledge base of risk prevention. In this way, PAS $1010 \mathrm{im}$ plicitly reproduces a mono-causal logic and technical knowledge base which resembles that in OHSAS 18001. This tendency to reproduce the logic of OHSAS 18001 can also be found when we look at the type of psychosocial issues that PAS 1010 addresses. We see a clear tendency to forward aspects of psychosocial work environment that can be conceptualized as single/isolated incidents that are targeted in the system by being reported as "near misses" and accidents (e.g., as single acts of violence, harassment, and bullying). It follows that the dimension of the psychosocial working environment that can be "objectified" thereby becomes the most visible indicator of psychosocial work environment at a work place.

Turning to the generic tendency in standards to focus on procedures and the basis of monitoring systems in audits, PAS 1010 has a clear focus on the procedures, for example, monitoring and documenting the risk assessment process. However, it does provide specific guidelines on, for example, which psychosocial risks to assess. The overall emphasis is on establishing, implementing, and maintaining procedures for the identification of risks. Consequently, the initial focus on PDCA may result in a migration of the more detailed guidelines on the production of hazards to a concern with the procedures and processes established in order to ensure risk prevention.

Regarding standards as abstract rules that must be translated into local knowledge (as well as translated back into abstract rules in order to show compliance), the PAS 1010 does seem to offer a list of contextual and organizational areas of concern. Here therefore, the guideline does not only consist of abstract rules but also on specific guidelines that may be easily adapted to different local contexts. It seems therefore that PAS 1010 , by including a range of concrete suggestions and specifications on what part of the work context that needs to be included in risk assessment, makes it easier to resolve the generic problem of local translation inherent in standards. 
Finally, standards have been criticized for not being based on scholarly knowledge but on stakeholder negotiations. To some extent, this is the case with PAS 1010 as well. Accounts of the process involved in creating PAS 1010 (Leka et al., 2011) suggest that disagreements about the extent to which standards might actually be the best solution in the regulation of the psychosocial work environment have resulted in some stakeholders not wanting to support the guidelines becoming a standard. In particular, it seems that disagreements about the objectivity of psychosocial work environment issues and the lack of acknowledgement of many of these issues are largely political by nature, preventing agreement in this area.

\section{Conclusion: How can international standards contribute to the regulation of psychosocial work environment issues?}

International standards are increasingly being used as means of regulation in a global labor market. This has raised questions about how such standards can contribute to OHS in general and to addressing and controlling growing psychosocial work environment problems in particular. Prevailing OHS standards, particularly OHSAS 18001, have been criticized for not adequately addressing increasing problems of the psychosocial work environment such as work-related stress and burn-out (Leka et al., 2011) as well as specific hazards such as employment insecurity, work intensification, and lack of influence (Hohnen \& Hasle, 2011; Walters \& Frick, 2000).

We have defined international standards as abstract rules claimed to be voluntary, have a source, and be explicit. International standards store knowledge in abstract rules, which make them suitable to deal with technical, monocausal knowledge rather than with the kind of professional practice knowledge that characterizes the knowledge relevant for the understanding of psychosocial work environment problems. The focus in standards is on developing and documenting procedures and processes rather than the subject matter of the work environment itself. In particular, in the case of the psychosocial work environment-which has many causes, is subjectively experienced, and is also highly political-this focus does not ensure the inclusion of all relevant issues. Furthermore, the idea that risks can be controlled by audits presupposes that psychosocial work environment can be related to (visible) non-compliance behavior rather than the structural and organizational context that is often pointed out as crucial by researchers. Finally, international standards need to build on abstract knowledge in order to become widely used - hence, standards must be translated into local practice that again must be translated back into abstract rules in order to be monitored within the system. There are several implications of this latter point. First, standards may not create homogeneity, but may indirectly promote variation by creating space for local adaption. Although this opens opportunities for developing local solutions aimed at solving local work environment issues, this also raises concern about the extent to which standards ensure a certain quality level of (psychosocial) working environment in practice. Second, the abstract nature of standards offers limited concrete guidelines for organizational management of psychosocial work environment problems. Finally, the fact that local practices also have to be 'translated back' to a more abstract level in order to document compliance with the standard, may create a certain space of possibilities, privileging solutions that may easily be monitored by audit procedures. 
The development of PAS 1010 can be interpreted as an attempt to develop a different type of thinking within the framework of international standards, and as such, it offers an interesting case of analysis. The analysis of PAS 1010 shows that it is possible to diminish some of the problematic tendencies of the abstract standards such as OHSAS 18001 without renouncing the very idea of risk management by standards as such. PAS 1010 has managed to include a notion of workers as experts in their own work environment not only as receivers of information but also as responsible in identifying a range of psychosocial work environment hazards. PAS 1010 also provides concrete guidelines, based on prevailing knowledge about the type of organizational and structural configurations that may result in psychosocial work environment problems. As such, it acknowledges the fact that psychosocial work environment problems are complex and a product of an interaction of several factors that can be difficult to disentangle from each other. The focus on the production of psychosocial problems as originating from a broader of field of management and organization, including organizational areas of Human Resources and work, makes it possible to rely on prevailing research knowledge about what constitutes psychosocial work environment risks.

However, there are also drawbacks in PAS 1010 that may limit its potential. PAS 1010 has copied the model of PDCA from prevailing standards such as ISO 9000 and OHSAS 18001. These standards are characterized by having a clear focus on procedures and processes of documentation and by a reliance on abstract, technical, objectivist, and monocausal knowledge. It is not immediately apparent how such a knowledge base can be combined with the (proclaimed) different epistemological understanding of work environment problems and their causes in PAS 1010. Concretely, this dilemma is exemplified in differences in vocabulary. PAS 1010 rests on evidence-informed knowledge; however, it is not specified how this is supposed to be different from the stronger term evidence-based knowledge in OHSAS 18001. PAS 1010 claims to promote a participative and more structurally oriented holistic perspective on work and work environment; however, it still remains to be seen how the prevailing ambiguities can be reconciled in practice.

Our analysis of the standards behind certified OHS management systems indicates a range of possible problems; at the same time, the standards also suggest that the new ways of thinking in standards (as exemplified by PAS 1010) create openings for the adaption of technical standards to local needs. It is therefore important to carry out further empirical studies of the implementation of PAS 1010 by analyzing practices in organizations with OHS managements systems.

\section{References}

Ahrne, G., Brunsson, N. and Garsten, C. (2000), “Standardization through Organization”, in Brunsson, N. and Jacobsson B. (eds.) A World of Standards, Oxford: Oxford University Press, pp. 1-21.

Berger, P. and Luckmann, T. (1966), The social construction of reality: A treatise in the sociology of knowledge, New York: Anchor Books.

Blewett, V. and O'Keeffe, V. (2011), “Weighing the pig never made it heavier: Auditing OHS, social auditing as verification of process in Australia, Safety Science, vol. 49, pp. 1014-1021. 
Boiral, O. (2012), "ISO Certificates as Organizational Degrees? Beyond the Rational Myths of the Certification Process", Organization Studies vol. 33, no. 5-6, pp. 633-654.

Brunsson, N., Rasche, A. and Seidl, D. (2012), "The Dynamics of Standardization: Three Perspectives on Standards in Organization Studies", Organization Studies, vol. 33, no. 5-6, pp. 613-632.

Brunsson, N. and Jacobsson, B. (2000), “The Contemporary Expansion of Standardization”, in Brunsson, N and Jacobsson B. (eds.) A World of Standards, Oxford: Oxford University Press, pp. 1-21.

Brunsson, N. (2000), "Organizations, Markets and Standardization” in Brunsson, N and Jacobsson B. (eds.) A World of Standards, Oxford: Oxford University Press, pp. 21-50.

Brunsson, N. (2000), "Standardization and Uniformity", in Brunsson, N. and Jacobsson B. (eds.) A World of Standards, Oxford: Oxford University Press, pp. 138-151.

BSI (2011), PAS 1010: Guidance on the management of psychosocial risk in the work place. British Standard Institution.

DS/OHSAS 18001 (2008), Occupational health and safety management systems - specification, København: Dansk Standard.

Flyvbjerg, B. (2006), "Five misunderstandings about case-study research", Qualitative Inquiry, vol. 12, pp. 219-245.

Frick, K and Kempla, V. (2011), "Voluntary OHS Management Systems - when are they good for your health?" Mälardalen University, Sweden, and ETUI, Brussels.

Frick, K. and Wren, J. (2000), "Reviewing occupational health and safety management - multiple roots, diverse perspectives and ambiguous outcomes”, in Frick et al. (eds.) Systematic Occupational Health and Safety Management, Oxford: Pergamon, pp. 17-42.

Furusten, S. (2000), "The Knowledge Base of Standards", in Brunsson, N and Jacobsson B. (eds.) A World of Standards, Oxford: Oxford University Press, pp. 71-85.

Gallagher, C., Underhill, E. and Rimmer, M. (2001), "Occupational Health and Safety Management Systems: A Review of the Effectiveness of OHS Management Systems in Securing Healthy and Safe Workplaces", National Occupational Health and Safety Commission.

Giddens, A. (1990), “The Consequences of Modernity”, Cambridge: Polity Press.

Hasle, P. (2010), "Certificeret arbejdsmiljøledelse i et historisk perspektiv", in Rocha og Hohnen (eds.) Ledelse af Arbejdsmiljø - Certificering $i$ praksis, Nyt Teknisk Forlag, pp. 27-37.

Hasle, P. and Zwetsloot, G. (2011), "Editorial: Occupational Health and Safety Management Systems: Issues and Challenges”, Safety Science, vol. 49, pp. 961-963.

Heinrich, H. W. (1959), “Industrial Accident Prevention”, 2nd edition New York: McGrawHill.

Hohnen, P. and Hasle, P. (2011), “Making work environment auditable - A 'critical case' study of certified occupational health and safety management systems in Denmark", Safety Science, vol. 49, pp. 1022-1029.

Hohnen, P, and Granerud, L (2010), "Forståelser af arbejdsmiljø på certificerede virksomheder" in Rocha og Hohnen (eds.) Ledelse af Arbejdsmiljø-Certificering i praksis, Nyt Teknisk Forlag, pp. 98-114.

Hopkins, A. (2000), Lessons from Longford: The ESSO Gas Plant Explosion, CCH Australia, Sydney.

ILO (2001), Guidelines on occupational safety and health management systems, ILO-OSH 2001.

Geneva: International Labour Office, 2001 Guide: occupational safety, occupational health, national level, enterprise level, technical aspect. 13.04.2.

Jacobsson, B. (2000), "Standardization and Expert Knowledge", in Brunsson, N. and Jacobsson B. (eds.) A World of Standards, Oxford: Oxford University Press, pp. 40-49. 
Leka, S., Jain, A., Widerszal-Bzyl, M., Zolnierczyk-Zreda, D. and Zwetsloot, G. (2011), "Developing a standard for psychosocial risk management: PAS 1010, Safety Science, vol. 49, pp. 1047-1057.

Power, M. (2003), "Evaluating the audit explosion”, Law \& Policy, vol. 25, pp. 185-202.

Power, M. (1997), “The Audit Society: Rituals of Verification”, Oxford: Oxford University Press.

Power, M. (1996), "Making Things Auditable”, Accounting, Organizations and Society, 21, 2/3, pp. 289-315.

Robson, L. et al (2007), "The effectiveness of occupational helath and safety management system interventions: A systematic review”, Safety Science, vol. 45, pp. 329-353.

Rocha, R. (2010), "Institutional effects on occupational health and safety management systems", Human Factors and Ergonomics in Manufacturing and Service Industries, vol. 20, no. 3, pp. 211-225.

Star, S. L. and Lampland, M. (2009), "Reckoning with Standards" in Lampland, M. and Star, S. L. (eds.) Standards and Their Stories. How Quantifying, Classifying, and Formalizing Practices Shape Everyday Live, Ithaca and London: Cornell University Press, pp. 3-35.

Timmermans, S. and Epsterin, S. (2010), A world of Standards but not a Standard World: Toward a Sociology of Standards and Standardization, in Annual Review of Sociology, vol. 36, pp. 69-89.

Walters and Frick (2000), "Worker Participation and the Management of Occupational Health and Safety: Reinforcing or Conflicting Strategies?" in Frick, K., Jensen, P., Quinlan, M. and Wilthagen, T. (eds.) Systematic Occupational Health and Safety Management, Oxford: Pergamon, pp. 43-66. 